\title{
AN OPEN-SOURCE MOBILE GEOSPATIAL PLATFORM FOR PROMOTING CLIMATE-SMART LIVELIHOOD-LANDSCAPE SYSTEMS IN FIJI AND TONGA
}

\author{
Kevin P. Davies ${ }^{1, *}$, John Duncan ${ }^{2}$, Nathan Wales $^{3}$, Renata Varea ${ }^{3}$, Helena Shojaei $^{2}$, Eleanor Bruce $^{1}$, Bryan Boruff ${ }^{2}$, Ellie Biggs ${ }^{2}$ \\ ${ }^{1}$ School of Geosciences, The University of Sydney, NSW, 2006, Australia - kpdavies@ uni.sydney.edu.au \\ ${ }^{2}$ UWA School of Agriculture and Environment, The University of Western Australia, Crawley WA, 6009, Australia \\ ${ }^{3}$ School of Geography, Earth Science and Environment, The University of the South Pacific, Suva, Fiji
}

Commission IV, WG IV/4

KEY WORDS: Geospatial, ICT4D, Open-Source, QGIS, QField, Fiji, Tonga

\begin{abstract}
:
Communities in Fiji and Tonga rely on landscape services to support a variety of livelihoods. These communities are increasingly vulnerable to climate (e.g. increasing cyclone occurrence and intensity) and environmental (e.g. mining and deforestation) stressors. Within these landscape systems, accurate and timely monitoring of human-climate-environment interactions is important to inform landscape management, land use policies, and climate-smart sustainable development. Data collection and monitoring approaches exist to capture landscape-livelihood information such as surveys, participatory GIS (PGIS), and remote sensing. However, these monitoring approaches are challenged by data collection and management burdens, timely integration of databases and data streams, aligning system requirements with local needs, and socio-technical issues associated with low-resource development contexts. Such monitoring approaches only provide static representation of livelihood-landscape interactions failing to capture the dynamic nature of vulnerabilities, and benefit only a small user base. We present a prototype of a mobile, open-source geospatial tool being collaboratively developed with the Ministries of Agriculture in Fiji and Tonga and local stakeholders, to address the above shortcomings of PGIS and other environmental monitoring and data sharing approaches. The tool is being developed using open-source mobile GIS technologies following a formal ICT for Development (ICT4D) framework. We discuss the results for each component of the ICT4D framework which involves multiple landscape stakeholders across the two Small Island Developing States. Based on the ICT4D user requirements analysis, we produced a prototype open-source mobile geospatial data collection, analysis and sharing tool. New dynamic spatial data layers related to landscape use and climate were specifically developed for use in the tool. We present the functionality of the tool alongside the results of field-testing with stakeholders in Fiji and Tonga.
\end{abstract}

\section{INTRODUCTION}

Landscapes of Pacific Island Countries (PIC) comprise myriad ecosystems which generate flows of services that are important for people's livelihoods. The functioning of these ecosystem service (ES) flows are sensitive to short-term variation in weather and long-term changes in climate. Ecosystems within PIC landscapes have differing sensitivities to weather and climate impacts, and different groups of people within landscapes benefit from different flows of ES (Duncan et al., 2019; Taylor et al., 2016; Daigneault et al., 2016). Therefore, the impacts of weather events and climate change will not be felt equally by all landscape inhabitants. Different configurations of landscapes, in terms of types of ecosystems and their spatial arrangement, will result in different capacities to cope and adapt to weather events and climate changes.

Spatially-explicit data capturing local detail on how people utilise landscapes (e.g. land-use and land-cover maps) and climatic variables that affect ecosystem functioning (e.g. extreme heat) are required to inform landscape management in the context of variable weather and changing climates. However, such datasets are not available or readily accessible to stakeholders engaged in landscape management in PICs. Quantitative ES maps often lack stakeholder participation or scenario analysis (Nahuelhual et al., 2015) and despite PGIS methods demonstrating potential for identification of ES, there

\footnotetext{
${ }^{*}$ Corresponding author
}

is little evidence that resulting data has influenced land-use decision making (Brown and Fagerholm, 2015). Further, landscapes and livelihoods are dynamic (Béné et al., 2016; Wairiu, 2017) and effective landscape management requires the capacity to monitor and respond to these dynamics. For local-level landscape stakeholders in PICs (e.g. agricultural extension officers, subsistence farmers) the capacity to capture such data is often challenging. In Fiji, for example, communities comprising groups of heterogeneous landscape users reported little interaction with agricultural extension officers who are the main local-level conduit of information from government ministries (Duncan et al., 2019). In Tonga, extension officers use paper-based methods to do crop surveys, requiring a lengthy, manual data input process at a central office, with the resulting digital data not then readily accessible.

The primary focus of this paper is to present the development of a mobile (tablet and smartphone) geospatial tool ('the tool') to enable stakeholders to visualise spatial datasets relevant to PIC landscapes. The tool will also provide functionality to augment these datasets through spatially-enabled data capture via survey forms and on-the-fly spatial data analysis. The goal is for information captured by the tool will inform climate-sensitive landscape management, and enable capture of granular information to allow for more accurate characterisation of a landscape, its uses, and stakeholders in decision making processes. We follow a field-validated ICT for Development (ICT4D) framework which emphasises iterative and collaborative development in low-resource contexts. 

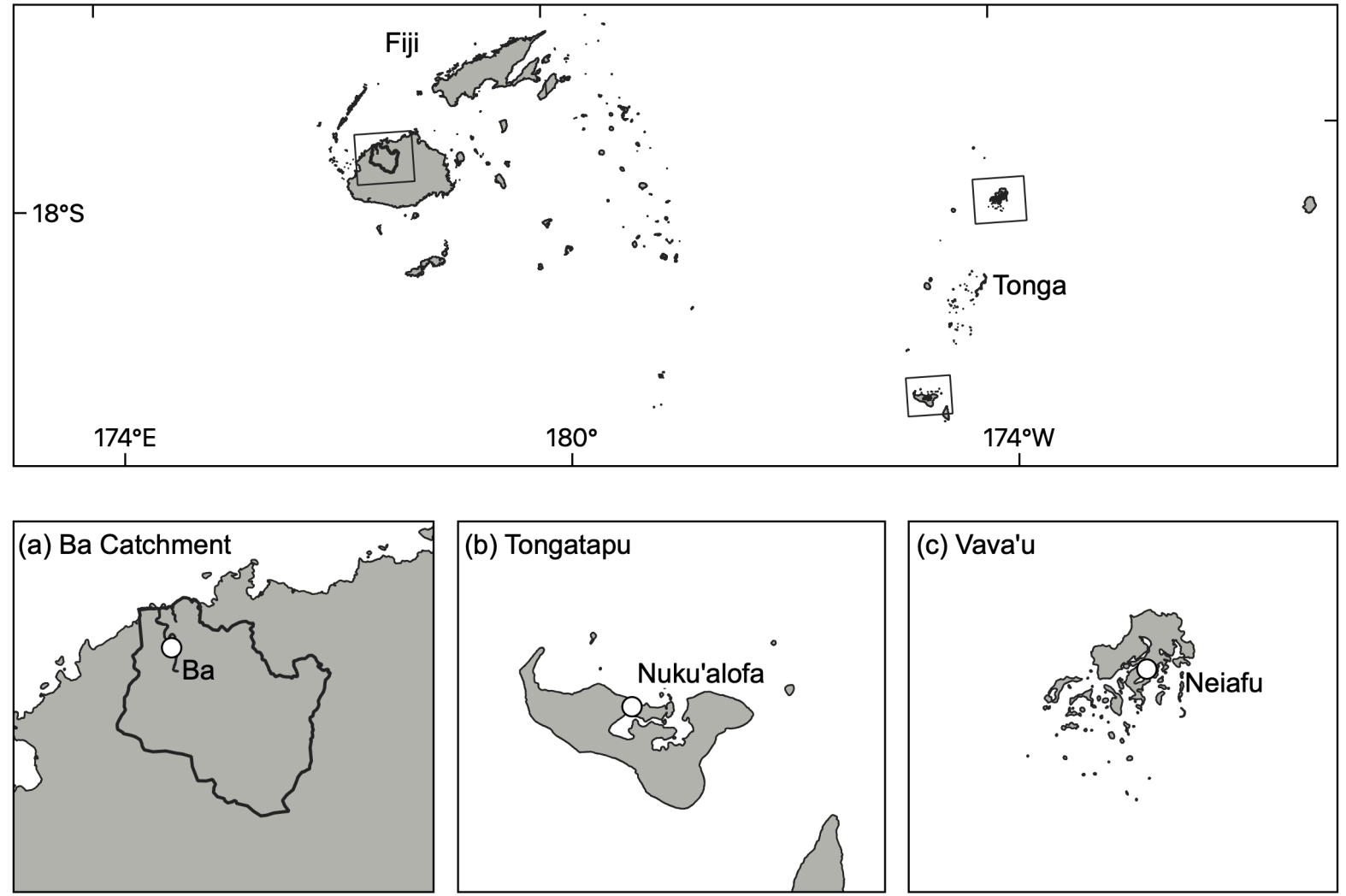

Figure 1. The tool is being co-developed with stakeholders in the (a) Ba Catchment, Fiji,

(b) Tongatapu, Tonga and (c) Vava'u, Tonga.

\section{STUDY AREAS}

We are co-developing the tool with stakeholders from three mixed-use landscapes across Fiji (The Ba Catchment) and Tonga (Tongatapu and Vava'u). All three landscapes (Figure 1) comprise ecosystems which supply services to support livelihoods, but have also faced severe climatic stressors.

\subsection{The Ba Catchment, Fiji}

The Ba Catchment is situated on the northeast of Fiji's main island, Viti Levu (Figure 1a). Mangroves are present along the coastal regions, mixed agricultural and sugarcane land uses dominate the mid-lower reaches of the catchment, and a mixture of forests, grassland, and agriculture span the upper reaches. Ba Province is the most populous in Fiji with 247,708 residents (FBoS, 2018). The Ba Catchment experiences intense climatic hazard events (e.g. Tropical Cyclone Winston in 2016). The wet season in $\mathrm{Ba}$ is during the austral summer with average monthly rainfall greater than $300 \mathrm{~mm}$ per month between January and March. This is also the warmest season and when there is the greatest frequency of extreme heat days: on average there are more than 20 days with maximum temperature greater than $30^{\circ} \mathrm{C}$ per month between November to April (NOAA, 2019). There is very high confidence the region will be affected by rising temperatures and sea level due to climate change (Australian Bureau of Meteorology and CSIRO, 2014).

\subsection{Tongatapu, Tonga}

Tongatapu is the main island of Tonga (Figure 1b) with a population of 74,611 from the most recent census (TSD, 2017). The island's land-use is predominantly agricultural or human settlement with some mangroves on the northern coast. Tongatapu consists of 42,497 acres of agricultural land which is $64 \%$ of the national total; of this agricultural land 16,006 acres is fallow (MAFFF et al., 2015). The landscape in Tongatapu is used to support a range of cropping, livestock, fishing, forestry, and handicraft activities; the majority of these activities are undertaken for subsistence or in a semi-subsistence manner (MAFFF et al., 2015). Tongatapu's wet season is during the austral summer with February and March receiving more than $200 \mathrm{~mm}$ rainfall, on average (NOAA, 2019). February and March are also the warmest months and the months that have the greatest frequency of extreme heat events (Australian Bureau of Meteorology and CSIRO, 2014).

\subsection{Vava'u, Tonga}

Vava'u is an island situated to the north of Tongatapu (Figure 1c) with a population of 13,738 . In Vava'u there is 11,549 acres of agricultural land with 2,190 agriculturally active households, the majority of which are subsistence and semi-subsistence with only $1 \%$ of agricultural households engaging in commercial production (MAFFF et al., 2015). Kava constitutes 64\% of the agricultural land in Vava'u (MAFFF et al., 2015). As in Tongatapu, households utilise the landscape to support a range of annual and perennial crops, livestock, fishing, and handicraft activities. 


\section{ICT4D FRAMEWORK}

We adopted an ICT4D framework proposed by Bon et al. (2016) consisting of five components (Figure 2). The framework is intended to support iterative development with ongoing stakeholder engagement: the components are not necessarily followed in order but can be configured as required. Here, we discuss our experience with the framework components, and although they are discussed in the order provided in Figure 2, this does not reflect the actual sequence of activities undertaken.

\subsection{Context Analysis}

Emphasis on awareness of local contexts is an important part of the ICT4D framework. Here, context and stakeholder analysis is an iterative and ongoing part of the development process to ensure the tool is aligned with stakeholder activities and institutional environments as well as addressing unmet needs.

Pilot work was undertaken to identify key stakeholders and their perceptions of key issues in PIC landscapes through focus groups and interviews with subsistence (natural resource using) communities, local community leaders, local government officials, national-level government officials, private sector organisations, development organisations, and non-government organisations (NGOs). The focus groups and interviews with communities sought to identify which ecosystem services people utilised, how people accessed landscape resources, the barriers people faced in accessing such resources, and how people sourced and utilised information to guide landscape decision making. Subsequent fieldwork including a detailed household survey in Fiji and participatory modelling activities in Fiji and Tonga have contributed to the context analysis.

The potential for key stakeholder groups to influence, and be impacted by, the tool development process was identified by adapting the approach outlined by Reed et al. (2009). The stakeholder groups analysed here include those whose activities are situated within the landscape such as subsistence and semi-subsistence landscape users, private sector organisations and commercial farmers, extension officers and local government officials, and those whose activities affect the landscape such as international development organisations and national level government officials and policy makers.

We partitioned stakeholders into two groups: primary and secondary stakeholders. Primary stakeholders were those whose livelihoods depend directly on ecosystem services (e.g. subsistence farmers), whilst secondary stakeholders interface directly or indirectly with primary stakeholders (e.g. agricultural extension officers, government agencies, NGOs).

\subsection{Needs Assessment}

Needs assessment refers to the identification and prioritisation of unmet needs for the use of geospatial data, or an unmet need which could be clearly or directly alleviated through the use of geospatial data. Bon et al. (2016) defines needs as a 'state of deprivation of some basic satisfaction' and can be independent of a specific technology or system.

Our needs assessment involved three stages: (1) discovery of unmet user needs in terms of geospatial information delivery and capture using focus groups; (2) prioritisation of unmet user needs using a set of objective criteria; and (3) selection of potential users for the first field trial of the tool. Needs
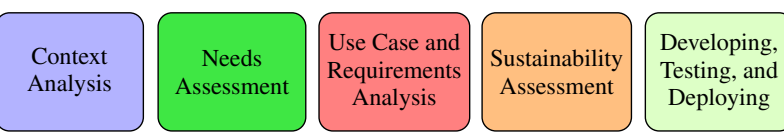

Figure 2. The five components of the ICT4D Framework adapted from Bon et al. (2016).

assessment was initially focussed on secondary stakeholders only with primary stakeholders to be included in a further iteration of the development cycle.

3.2.1 Unmet User Needs. In November 2018 a selection of secondary stakeholders were invited to focus group discussions in Suva and Lautoka in Fiji, and Tongatapu in Tonga. Several broad questions were used to lead the focus group discussion:

- What is your job role or function?

- What geospatial data do you currently collect or use?

- How do you get access to existing geospatial information?

- How do you collect new geospatial information?

- What geospatial data needs do you have that are unmet?

- Are there any technical or organisation barriers to accessing existing geospatial information that you need?

The focus groups resulted in very rich descriptions of some of the challenges faced by the stakeholders with regards to geospatial information relevant to their particular job roles and location. However, there were some common themes across all stakeholders. This allowed us to group unmet needs into five thematic categories $\left(1^{\text {st }}\right.$ column in Table 1$)$.

3.2.2 Prioritisation of Unmet User Needs. Narrowing of the potential functional scope of the initial tool was necessary in order to trial a prototype that addressed unmet needs common to all stakeholders for both study sites, and that were both logistically and technically feasible. Unmet needs were therefore prioritised within each of the above broad categories using five criteria: cost, technical feasibility, data availability, user capacity, and scalability. Each of the identified needs were ranked as high, medium, or low priority against each of these criteria. The unmet needs with the overall highest priority in each of the five thematic categories were chosen for trialling in the initial prototype of the tool (Table 1).

3.2.3 Selection of Potential Users. Reducing the size of the secondary stakeholder group who would participate in the use case and requirements analysis (described below), and the initial field trial of the tool was necessary for logistical and cost reasons. Extension officers (both agricultural and forestry/conservation) were identified as a potential user group for the trial of the tool. This was for three reasons: (1) their clear need for geospatial data (e.g. land use maps), (2) their need for data capture tools (e.g. crop surveys), and (3) because they work directly with a range of landscape users (i.e. primary stakeholders such as subsistence farmers).

\begin{tabular}{|l|l|}
\hline Thematic Group & Priority Unmet Needs \\
\hline Geospatial data & Crop Type Map \\
Geospatial data collection & Crop Survey \\
Mobile geospatial analysis & Climate \& Weather Analysis \\
Reference geospatial info. & Land cover \& Land Use \\
Geospatial data sharing & (no high priority need) \\
\hline
\end{tabular}

Table 1. Priority unmet needs by thematic group. 


\subsection{Use Case \& Requirements Analysis}

Use cases and narratives (or user stories) are a requirements analysis technique that focuses on the interaction between 'actors' (in this case the potential users) and the ICT system being developed (in this case the tool) without describing a technical implementation. We developed use cases and narratives for the tool by using the stakeholder's descriptions of their unmet needs as well as our direct experience working with the stakeholders throughout the project. A total of 10 use cases were developed for each of the thematic groupings of high priority unmet needs (Table 2). For each of the defined use cases, a plain language narrative and a use case diagram were produced using the Eclipse Papyrus open-source modelling tool (Eclipse Foundation, 2019).

\begin{tabular}{|l|l|}
\hline$\#$ & Use Case \\
\hline 1 & Survey crop damage after a tropical cyclone. \\
2 & Report on area cultivated by crop type. \\
3 & Identify suitable lands for new crop type. \\
4 & Survey different crop types cultivated for a region. \\
5 & Report on area of change to land cover. \\
6 & Determine crop suitability to future climate scenarios. \\
7 & Map precipitation during/after a storm event. \\
8 & Report on areas suffering from drought. \\
9 & Overlay seasonal forecast and identify crops at risk. \\
10 & Overlay natural risk map and identify crops at risk. \\
\hline
\end{tabular}

Table 2. The set of use cases derived and refined by collaboration with potential users.

The first use case for the tool was 'survey crop damage after a tropical cyclone' and is presented here as an example (Figure 3 ). In many of the use cases, we have introduced other actors into the use case diagrams such as an expert 'Analyst' and 'Landscape Manager', however, the primary focus was on eliciting the needs of the potential user - the extension officer.

The use case diagrams and narratives were then provided to the set of secondary stakeholder users selected as the potential users of the tool. These potential users were then interviewed to determine whether the use cases were realistic and reflective of their requirements for the tool. A set of questions were used to guide the interviews:

- Is the use case relevant to your job function?

- Could the use case be modified to better reflect how you might interact with the tool?

- Are there other important use cases that we have not captured?

- Do you see any conflict, overlap or potential integration with other tools you use?

Based on the detailed feedback from these interviews, the use cases were adjusted or extended to better capture the user requirements. These use cases and requirements will be continued to be refined through the remainder of the project.

\subsection{Sustainability Assessment}

This is a government funded program with a fixed four year duration. Following project completion there is a real risk that the developed tool and corresponding spatial support layers will cease to operate due to lack of ownership, ongoing financial support, or adequate maintenance. Our project also faces challenges with multiple interested stakeholders operating across multiple jurisdictions.

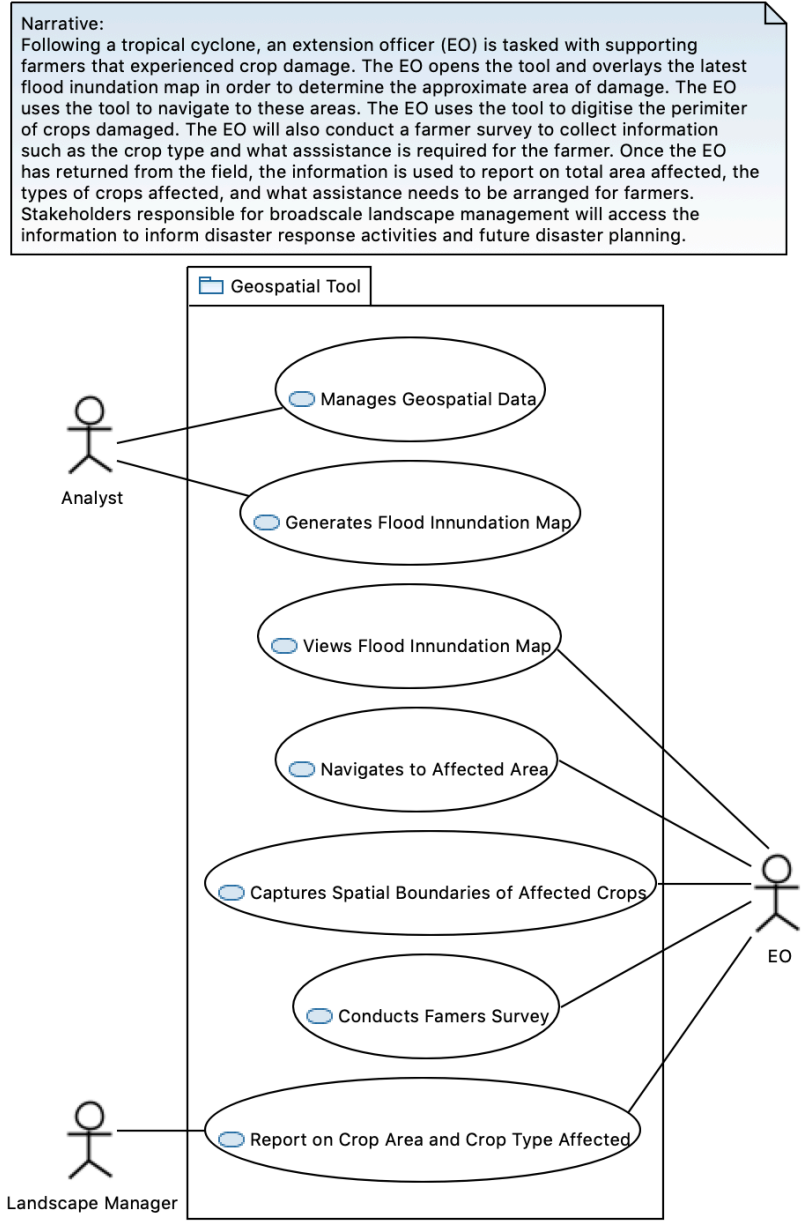

Figure 3. The narrative and diagram for the 'survey crop damage after a tropical cyclone' use case shows how

'actors' (an analyst, extension officer or EO, and

landscape manager) would interact with the tool.

The ICT4D framework attempts to explicitly address these issues by including' a Sustainability Assessment. Bon et al. (2016) demonstrates a quantitative, business-model approach to evaluate sustainability. However, for our project, benefits to stakeholders are not directly financial and are often intangible. Instead, we have compiled a list of questions (Table 3) that we will seek to evolve and address as the project progresses in order to reduce the likelihood of poor project sustainability.

We have also attempted to ensure sustainability by imposing technical constraints on the project. These constraints will include: that every software component must be free and open-source, server components must be able to deployed to a cloud service such as Google Cloud Platform or Amazon Web Services, mobile components must support Android, and the final architecture must be as automated as possible.

\begin{tabular}{|l|l|}
\hline Issue & Current Status \\
\hline Who will 'own' and host the tool? & Resolved \\
How will the tool be financed? & Unresolved \\
How will users be supported? & Unresolved \\
Who will do technical maintenance? & Unresolved \\
How will new data sources be added? & Unresolved \\
\hline
\end{tabular}

Table 3. Questions related to the long-term sustainability of the tool and the current status. 


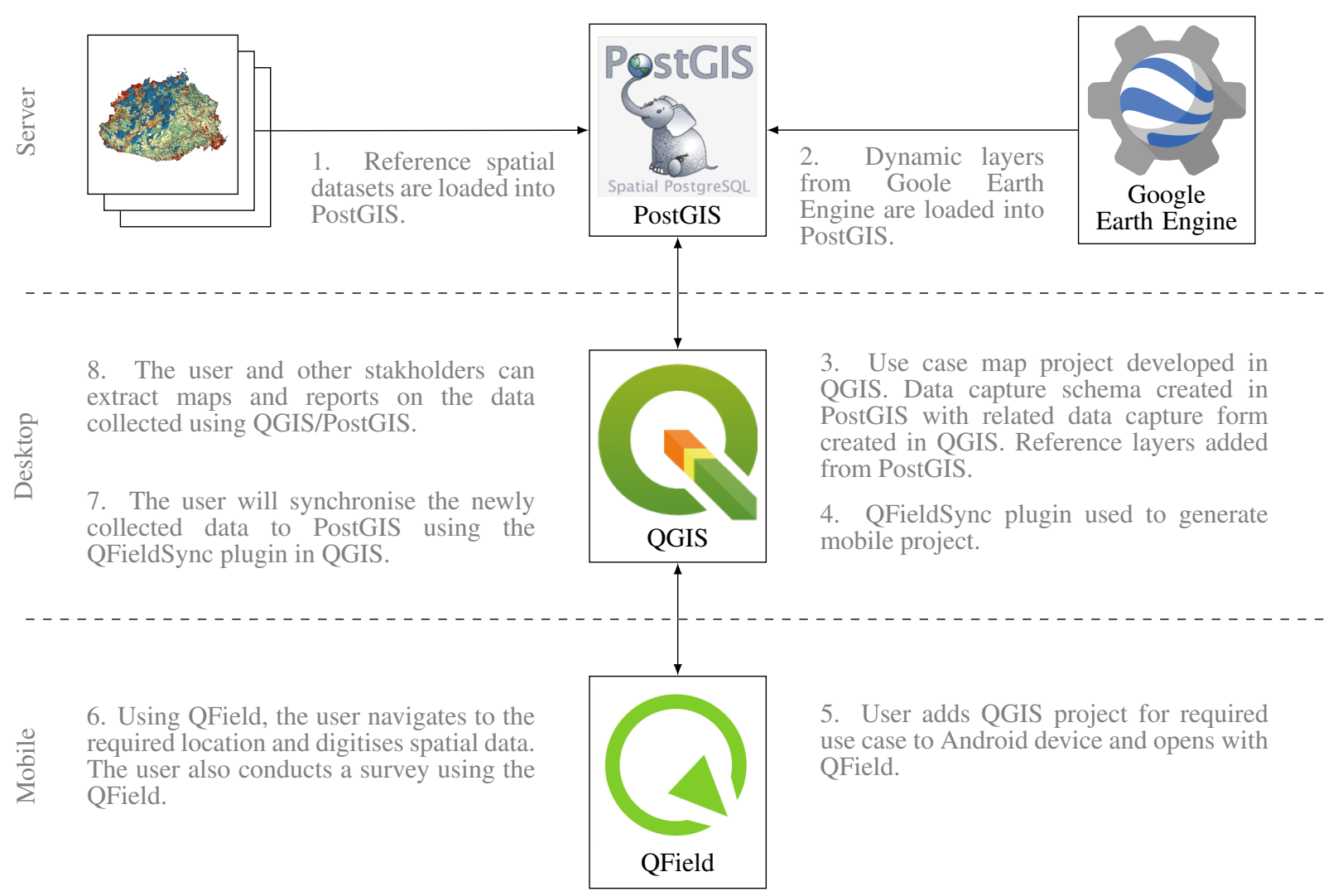

Figure 4. Conceptual design of the pilot tool, and a generic use case of the tool (numbered 1 to 8 ).

\subsection{Development, Testing and Deployment}

Our development efforts were focussed on enhancing an existing open-source geospatial data collection tool in order to reduce risks associated with developing new software and to address some of the issues related to the longer-term sustainability of the tool. Therefore, the preliminary stage of the 'development, testing and deployment' component of the ICT4D framework was to perform a desktop evaluation of existing, relevant mobile platforms to determine the best candidates for the first pilot implementation of the tool.

Over 100 candidate tools were identified via a web and grey literature search. Most candidates were identified from the 'Apps4Ag' database (Technical Centre for Agriculture, 2018). The desktop evaluation was carried out in two passes. The first pass evaluated each tool on three criteria: (1) support for offline data collection, (2) open-source software, and (3) ability to run on the Android mobile platform. Fourteen of the identified candidates met these three critical criteria.

The 2nd pass criteria were: (1) ability to display spatial data, (2) ability to navigate to spatial features using the device GPS, (3) ability to capture geographic features, (4) support multi-user environment, and (5) support server data storage either via an open, hosted service, or installation on a cloud service such as Amazon Web Services or the Google Cloud Platform. Two tools met this 2nd pass: QField (OPENGIS.ch, 2019a) and Input, a derivative of QField (Lutra Consulting, 2019).

QField is an open-source, mobile, and streamlined version of QGIS (QGIS Developers, 2019) designed for mobile spatial data visualisation and capture. QField is designed to display maps created in the QGIS desktop as well as to synchronise data captured in the field by QGIS using the QFieldSync plugin (OPENGIS.ch, 2019b). QField was chosen as the base platform for the pilot version of the tool.

PostGIS, an extension to the open-source PostgreSQL relational database (PostGIS Developers, 2019) was chosen as it provides a single repository for all reference spatial layers and survey data and supports a multi-user environment (with privacy controls) for future generations of the tool. QGIS also natively supports PostGIS layers.

Google Earth Engine was chosen to provide dynamic spatial data sets as it is freely available to non-commercial users, and provides a large collection of remote sensing products suitable for land cover mapping and climate analysis (Gorelick et al., 2017). It also provides a Python API that will allow for future automation of data ingestion into PostGIS.

The conceptual design of the tool (pilot version) is intended to support multiple use cases (Figure 4). Reference data layers (added to PostGIS) will come from existing spatial data collections and online data portals. Dynamic land cover and climate layers will be pulled from Google Earth Engine. A use case will have a QGIS map environment which will include relevant PostGIS reference layers, a PostGIS data schema, and a data capture form. The QGIS use case map is used in the QField app on a mobile device to visualise, interrogate and capture new spatial data. New spatial data is synchronised back to the PostGIS database for further analysis, reporting and sharing.

Field-testing of the prototype with stakeholders in Fiji and Tonga is scheduled for June and July 2019. We plan to collaboratively test and refine the tool in the field to further refine the use cases and requirements, and continue the evolutionary development of the tool. 


\section{CONCLUSIONS}

Challenges faced by PICs require accurate and timely spatial information, and a pathway to capture and share new information. However, the functions of such a technical response are unclear. The value of the iterative flexible ICT4D framework is providing a methodology to continually explore, refine and develop a spatial tool that will improve stakeholders' ability to make climate-smart landscape planning decisions.

\section{ACKNOWLEDGEMENTS}

We thank the communities of Nawaqarua, Etatoko, and Koronubu-Vunibaka (Fiji), and Kalaau, Talasiu, and Afa (Tonga) for their engagement in the co-development of the tool, and our collaborators for their ongoing contribution to this project including the Pacific Community (SPC), the NGO community, and government ministries in Fiji and Tonga. The project (UWA, 2019) is funded by the Australian Centre for International Agricultural Research (ACIAR; ASEM/2016/101).

\section{References}

Australian Bureau of Meteorology and CSIRO, 2014. Climate Variability, Extremes and Change in the Western Tropical Pacific: New Science and Updated Country Reports. Technical report, Australian Bureau of Meteorology and Commonwealth Scientific and Industrial Research Organisation, Melbourne, Australia.

Béné, C., Al-Hassan, R. M., Amarasinghe, O., Fong, P., Ocran, J., Onumah, E., Ratuniata, R., Tuyen, T. V., McGregor, J. A., Mills, D. J., 2016. Is resilience socially constructed? Empirical evidence from Fiji, Ghana, Sri Lanka, and Vietnam. Global Environmental Change, 38, 153-170. http://dx.doi.org/10.1016/j.gloenvcha.2016.03.005.

Bon, A., Akkermans, H., Gordijn, J., 2016. Developing ICT Services in a Low-Resource Development Context. Complex Systems Informatics and Modeling Quarterly, 84-109. https://csimq-journals.rtu.lv/article/view/csimq.2016-9.05.

Brown, G., Fagerholm, N., 2015. Empirical PPGIS/PGIS mapping of ecosystem services: A review and evaluation. Ecosystem Services, 13, 119-133. https://www.sciencedirect.com/science/article/pii/ S2212041614001235.

Daigneault, A., Brown, P., Gawith, D., 2016. Dredging versus hedging: Comparing hard infrastructure to ecosystem-based adaptation to flooding.

Duncan, J., Haworth, B., Boruff, B., Wales, N., Biggs, E., Bruce, E., 2019. Managing multifunctional landscapes: local insights from a Pacific Island Country context. Technical report, in review.

Eclipse Foundation, 2019. Papyrus Modeling Environment. https://www.eclipse.org (accessed: 2019-04-01).
Gorelick, N., Hancher, M., Dixon, M., Ilyushchenko, S., Thau, D., Moore, R., 2017. Google Earth Engine: Planetary-scale geospatial analysis for everyone. Remote Sensing of Environment, 202, 18-27. https://doi.org/10.1016/j.rse.2017.06.031.

Lutra Consulting, 2019. Input app. https://inputapp.io (accessed: 2019-04-01).

MAFFF, TSD, FAO, 2015. Tonga National Agricultural Census Main Report. Technical report, Ministry of Agriculture, Food, Forests and Fisheries; Tonga Statistics Department; Food and Agriculture Organization of the United Nations, Nuku'alofa.

Nahuelhual, L., Laterra, P., Villarino, S., Mastrángelo, M., Carmona, A., Jaramillo, A., Barral, P., Burgos, N., 2015. Mapping of ecosystem services: Missing links between purposes and procedures. Ecosystem Services, 13, 162-172. https://www.sciencedirect.com/science/article/pii/ S2212041615000340.

NOAA, 2019. Global Surface Summary of the Day. https://catalog.data.gov/dataset/global-surface-summary-of -the-day-gsod (accessed: 2019-04-01).

OPENGIS.ch, 2019a. QField app. https://qfield.org (accessed: 2019-04-01).

OPENGIS.ch, 2019b. QFieldSync plugin for QGIS. https://qfield.org/docs/qfieldsync (accessed: 2019-04-01).

PostGIS Developers, 2019. PostGIS. https://postgis.net (accessed: 2019-04-01).

QGIS Developers, 2019. QGIS: A Free and Open Source Geographic Information System. https://www.qgis.org (accessed: 2019-04-01).

Reed, M. S., Graves, A., Dandy, N., Posthumus, H., Hubacek, K., Morris, J., Prell, C., Quinn, C. H., Stringer, L. C., 2009. Who's in and why? A typology of stakeholder analysis methods for natural resource management. Journal of Environmental Management, 90, 1933-1949. http://dx.doi.org/10.1016/j.jenvman.2009.01.001.

Taylor, M., Lal, P., Solofa, D., Sukal, A., Atumurirava, F., Manley, M., Nonga, N., Groom, S., Starz, C., 2016. Agriculture and climate change: an overview. M. Taylor, A. McGregor, B. Dawson (eds), Vulnerability of Pacific Island agriculture and forestry to climate change, Pacific Community, chapter 3 .

Technical Centre for Agriculture, 2018. Apps4Ag. www.apps4ag.org (accessed: 2018-03-01).

TSD, 2017. Tonga 2016 Census of Population and Housing. Technical report, Tonga Statistics Department, Nuku'alofa.

UWA, 2019. University of Western Australia, Climate-Smart Landscapes for Promoting Sustainability of Pacific Island Agricultural Systems. www.livelihoodsandlandscapes.com (accessed: 2019-04-01)

Wairiu, M., 2017. Land degradation and sustainable land management practices in Pacific Island Countries. Regional Environmental Change, 17, 1053-1064.

FBoS, 2018. 2017 Population and Housing Census Release 1. Technical report, Fiji Bureau of Statistics, Suva. 